\title{
DIAGNÓSTICO DA INDÚSTRIA GRAMPEL PARA POSSÍVEIS SOLUÇÕES POR MEIO DO DESIGN
}

Larissa Angeoleti

Univille

larissa.angeoleti@gmail.com

Victor Lauriciano Aguiar

Univille

contato@ograndevendedor.com.br

\author{
Marina Pezzini \\ Univille \\ marinapzn@gmail.com \\ Haro Ristow Wippel Schulenburg \\ Univille \\ haro@univille.br \\ Rosangela Canonica \\ Univille \\ rcanoni@yahoo.com.br
}

Resumo: O presente estudo teve como objetivo desenvolver a Gestão do Design em nível estratégico, para uma empresa do ramo de serviços de corte à laser. Após uma tentativa mal sucedida de lançamento de produtos, aproveitando a sucata do processo produtivo, a empresa buscou o design como suporte para sua problemática. O estudo utilizou do design thinking como aporte metodológico, sendo este adaptado ao processo de gestão e marketing dando ênfase na fase de imersão, fase na qual se realizou análises internas e externas a fim de obter informações para a concepção de novas sugestões na gestão. Durante a fase imersão, elaborou-se um diagnóstico, detectando pontos fortes e fracos, ameaças e oportunidades, que possibilitaram a elaboração de definições e ações estratégicas. Dentre os desdobramentos, têm-se a divisão do estudo nos seguintes tópicos: A indústria Grampel e um breve histórico; Focos da análise realizada; Sintese da análise interna; Síntese da análise externa, e por fim, a apresentação do infográfico como forma de prototipar e organizar o processo de gestão sugerido. Desta forma, pode-se considerar que os objetivos propostos foram alcançados. A pesquisa foi submetida e aprovada pelo Comitê de Ética sob número do protocolo 051706/2014.

palavras-chave: gestão do design; diagnóstico; imersão; indústria.

\section{Abstract:}

This study aimed to develop the Design Management at a strategic level, for a company in the laser cutting services segment. After an unsuccessful attempt to launch products, taking advantage of the scrap of the production process, the company sought to design as support for their problems. The study used the design thinking as a methodological approach, which was adapted to the process of management and marketing with emphasis on the immersion phase, in which it were 
conducted internal and external analysis in order to obtain information for the design of new suggestions in management. During the immersion phase, a diagnosis was elaborated, identifying strengths and weaknesses, threats and opportunities, which enabled the development of definitions and strategic actions. Among the consequences, the study was divided in the following topics: The Grampel industry and a brief history; Emphases of the analysis; Synthesis of the internal analysis; Summary of the external analysis, and finally the presentation of an infographic as a way to prototype and organize the suggested management process. Thus, it was considered that the proposed objectives were achieved. The research protocol was approved by the Ethics Committee under the protocol number 051706/2014.

Keywords: Design management; Strategic Diagnosis; Strategic Actions; Incremental Innovation.

\section{INTRODUÇÃO}

Da constante busca pela inovação nas organizações emergem novas atuações que vão além dos limites tradicionalmente estabelecidos em determinados campos disciplinares da gestão. Nesse sentido, o design vem se consolidando com novas práticas e atuações mercadológicas. Observa-se que um projeto de design não é mais considerado apenas como um resultado que contemple soluções práticas, estéticas e funcionais. Com a atual discussão das práticas do design como um serviço, salienta-se a preocupação em propor soluções para a indústria. O design como um campo exploratório de atuações bem sucedidas, pode ainda, enriquecer o modelo de gestão que se tinha concebido previamente e tradicionalmente em áreas administrativas.

Diante do exposto, surge a problemática do estudo, avaliando a contribuição do designer e seu papel junto à indústria: Como desenvolver uma nova atuação de mercado para a indústria Grampel? Nesse sentido, têm-se como objetivo geral desenvolver a gestão do design em nível estratégico na Grampel. Para tanto, considera-se a realização do diagnóstico estratégico, definição de estratégias e ações e elaboração de infográfico como maneira de prototipar os resultados. Após contato inicial com a indústria, percebeu-se uma interessante oportunidade para o designer atuar. Para a realização da pesquisa, utilizaram-se pressupostos metodológicos do design thinking. A metodologia é utilizada para identificar respostas em um diagnóstico na fase de imersão. Nas etapas de análises foi utilizada a matriz Strenth, weaknesses, opportunities and threats - SWOT em formato de tabela, dividida em quatro quadrantes que formam a sigla SWOT. Esta é uma ferramenta relevante para o planejamento estratégico empresarial pois permite observar os fatores internos e externos e os elementos que os compõem (OLIVEIRA, 2010). Optou-se como modalidade de pesquisa o estudo de caso com abordagem qualitativa exploratória por meio de instrumentos de observação e entrevistas. A escolha do método de estudo de caso deu-se pela intenção de investigar e descrever o caso de uma indústria da região a qual procurou a pesquisadora com interesse em novas atuações e propostas mercadológicas. $O$ estudo de caso contempla a pesquisa também pelo fato de relatar as observações e intervenções que se pretende adotar para atender a demanda da 
indústria em questão. Uma das características do método estudo de caso é a "capacidade de lidar com uma ampla variedade de evidências - documentos, artefatos, entrevistas e observações" (YIN, 2001, p. 27). Esse formato, porém, foi adaptado às necessidades da presente pesquisa, relacionando a Gestão do Design à metodologia do design thinking e suas etapas, considerando-o um objeto de estudo específico. Nesse sentido, o presente estudo inicia com a apresentação da indústria objeto de estudo, posteriormente apresenta o foco das análises interna e externa seguida da síntese das mesmas e, finaliza com o infográfico prototipando as sugestões do diagnóstico realizado.

\section{A INDÚSTRIA GRAMPEL}

A Grampel é uma indústria situada em Joinville prestadora de serviços em soluções de cortes a laser. Focada no ramo metal mecânico, a indústria atua no mercado desde 1982, inicialmente em um galpão alugado. Em 1991, constituiu sede própria com $300 \mathrm{~m}^{2}$ de área construída e houve a troca da razão social para a atual marca Grampel. Com o aumento de clientes, em 1998, a indústria adquiriu um terreno de $7000 \mathrm{~m}^{2}$, dos quais $1100 \mathrm{~m}^{2}$ são de área construída.

O início da pesquisa se deu após o convite do diretor da indústria para uma visita técnica seguida de uma entrevista semiestruturada para fins de observações preliminares. O diretor procurou o programa de Pós-Graduação em Design da Univille com a pretensão de criar produtos próprios, além de buscar alternativas viáveis para sua atual capacidade produtiva. Após o convite, a visita de campo ocorreu em julho de 2013, possibilitando um diagnóstico inicial e coletando dados para o desenvolvimento da pesquisa, considerando suas expectativas, interesses e oportunidades aparentes.

Ainda nessa visita, percebeu-se que a indústria gera um volume expressivo de resíduos, que sugere a necessidade de pesquisas para minimizar seus efeitos no meio social e ambiental, equilibrando também fatores econômicos. A Grampel descarta uma caçamba de resíduos por semana, o que resulta em 28 metros cúbicos de resíduos por mês. Suas matérias-primas principais são o alumínio e o aço que representam, respectivamente, o valor de $R \$ 2,90$ e $R \$ 2,10$ por quilograma de sucata. A fim de equilibrar objetivos econômicos e mercadológicos com valores ambientais e sociais, a indústria considerou que os resíduos metálicos poderiam oportunizar, por meio do design, soluções inovadoras de produtos.

Percebeu-se o pouco conhecimento na área do design, motivo que poderia causar frustações futuramente. Nesse sentido, buscou-se evidenciar para o diretor da indústria a necessidade de considerar o planejamento e a gestão como pontos determinantes do êxito no lançamentos de novos produtos. Para tanto, seria necessário gerir um processo coeso e estratégico, além do desenvolvimento e criação de uma linha de produtos. Alguns aspectos necessários para atender o mercado foram questionados, como: comercialização, marca, posicionamento. Sendo esclarecido pela pesquisadora que o papel do designer no cenário atual, de novas práticas de atuação, é executar um estudo de serviços na área da gestão, com ferramentas e metodologias que contribuam para viabilizar tal projeto com eficiência. A intenção foi demonstrar que criar bons produtos não garante um mercado promissor, conforme aponta Mozota (2011, p. 145): “... um bom produto não é suficiente para o sucesso da inovação: Estudos anteriores enfatizam a importância da gestão no desempenho da inovação." 
Para que a ideia inicial da Grampel no desenvolvimento de produtos obtenha o sucesso desejado, conclui-se que esta pesquisa precisa prestar uma contribuição mercadológica. Para planejar o lançamento de produtos, faz-se necessário diagnosticar a situação e o posicionamento da indústria e agir estrategicamente em ações futuras. De maneira a apontar um lançamento de produto com um planejamento mais criterioso, fica evidente a estruturação de diagnóstico como uma questão de embasamento para gerir e organizar essa intenção de desenvolvimento de produtos. Nesse sentido, esta pesquisa visa contribuir para o incremento da ciência e da prática no que diz respeito às áreas de design, gestão e inovação na indústria. $O$ alinhamento estratégico da gestão do design para a atuação da indústria Grampel constitui uma oportunidade atrativa de mercado, podendo gerar uma vantagem competitiva com os recursos e capacidade produtiva que a empresa já possui.

\section{FOCOS DE ANÁLISE NA INDÚSTRIA}

Este item relata a fase de imersão, proposta para o diagnóstico estratégico na Grampel. A fase de imersão desmembrou-se em análises interna e externa, realizadas com a ferramenta SWOT, da qual resulta um quadro objetivo das ameaças e oportunidades, forças e fraquezas, podendo direcionar as futuras definições estratégicas (KOTLER, 2003). A análise interna é um dos elementos que fornece subsídios para criação do quadro SWOT. Para tanto, apresentam-se os pontos fortes e pontos fracos coletados e identificados internamente, desde a etapa inicial da pesquisa, até o aprofundamento dos estudos. Identificam-se como pontos fortes na análise interna, os fatores e diferenciais da Grampel que podem significar vantagem competitiva. Como pontos fracos, relacionam-se algumas deficiências e limitações que possam intervir no desempenho de mercado e no cenário em que a Grampel poderá atuar.

Nesse viés, consideram-se as ações compatíveis com uma possível atuação mercadológica para o desenvolvimento de produtos direcionados ao novo mercado de atuação, a fim de estipular metas para o andamento das fases seguintes. A análise contemplou tópicos apontados por Aarker (2001), Mozota (2011), Martins e Merino (2011), autores que discorrem sobre os possíveis requisitos para diagnóstico estratégico organizacional. Tendo em vista os temas pertinentes, apresenta-se a figura 01 com os requisitos principais de análise interna realizados na Grampel. 


\begin{tabular}{|l|l|}
\hline $\begin{array}{l}\text { REQUISTOS } \\
\text { Design }\end{array}$ & $\begin{array}{l}\text { FOCOS DA ANÁLISE } \\
\text { De que maneira a indústria contempla ou imagina } \\
\text { como ferramenta? }\end{array}$ \\
\hline Branding / Posicionamento & Como se planeja o posicionamento de marca? \\
\hline Máquinas & Quais equipamentos e Instalaçōes? \\
\hline Materiais & Quais especificidades do material a ser explorado? \\
\hline Mão de Obra & $\begin{array}{l}\text { Qual seria a capacitação e desenvolvimento } \\
\text { dos profissionais? }\end{array}$ \\
\hline Meio Ambiente & $\begin{array}{l}\text { Como se fomentará a sustentabilidade ecônomica } \\
\text { e ambiental? }\end{array}$ \\
\hline $\begin{array}{l}\text { Gerenciamento e Lançamento } \\
\text { de Produtos }\end{array}$ & Como gerir a nova atuação? \\
\hline Marketing & Como lançar campanha e vender produtos? \\
\hline
\end{tabular}

Figura 01 - Requisitos analisados

Fonte: Elaborado pelos autores, com base na pesquisa realizada (2014)

Os métodos utilizados para a análise interna no decorrer da pesquisa foram relatos, observações e entrevistas, dos quais apresentam-se os resultados coletados.

\section{SÍNTESE DA ANÁLISE INTERNA: ENTREVISTAS E OBSERVAÇÕES}

No requisito design, foram levantados os dados por meio de observações durante visitas à indústria e complementados com entrevista, por meio de um formulário semi-estruturado. Na entrevista, o diretor relatou que a Grampel não possui um produto próprio e, como seus serviços não são seriados, fica limitada a um grupo específico de clientes. Como as compras desses clientes são esporádicas, há períodos em que os profissionais e as máquinas ficam ociosos. O diretor tem interesse em criar um centro de design dentro da indústria. Embora demonstre pouco conhecimento sobre o design, considera a profissão indispensável no desenvolvimento de produtos e relevante fator de impacto mercadológico perante à concorrência. Aponta como um fator que o instigou a investir em design a concorrência desleal dos produtos importados da China, citando o design como um aspecto de diferenciação de produtos.

Quando questionado sobre branding, o diretor discorre sobre inúmeras possibilidades de desenvolvimento de produtos, comparando marcas do segmento decorativo do mercado da região. Neste cenário, ele enfatiza a necessidade de posicionar a Grampel em um novo mercado, com uma nova marca. Quanto aos materiais, declarou que o aço e o alumínio, utilizados em seus processos, fazem parte de sua maior motivação para a criação da nova atuação mercadológica. Esses materiais são vistos como nobres em diversos produtos no segmento decorativo, demonstrando ser o campo de atuação ideal imaginado por ele. Partindo da premissa de que se tem o material a ser explorado, iniciou-se a busca por informações referentes ao maquinário, que auxiliou no levantamento de dados. 
Com soluções de cortes a laser de alta tecnologia, a Grampel atende toda o sul do país com serviços de corte, dobra e solda de chapas planas de aço, com processos metal-mecânicos e maquinário de alta performance. Os materiais que usa no maquinário apresentados no quadro 1 são: aço carbono, cortando na espessura de até $15,87 \mathrm{~mm}$, aço inox, com espessura de até $6,35 \mathrm{~mm}$ e alumínio, espessura de até $4 \mathrm{~mm}$. Para fabricar e entregar as peças prontas para o cliente, a Grampel executa serviços de refinamento e acabamento de algumas peças, como soldas, dobras e furação.

Como apoio na realização dos seus serviços, a indústria contempla a mão de obra com um setor de engenharia de processo onde emprega quatro colaboradores com formação na área de projetos metal mecânicos. Esse setor realiza projetos com softwares e sistema de apoio. Os softwares utilizados nos processos e alinhados na comunicação com o máquinario são: SolidWorks, Lantek e Autocad. O SolidWorks e o Autocad são softwares que desenvolvem projeto de peças tridimensionais e bidimensionais, já o Lantek é utilizado na programação, gerenciamento e automatização de máquinas, distribuindo as peças projetadas em linha de produção.

Considerando que se trata de uma indústria prestadora de serviços e que não tem produtos próprios, a Grampel não investe significativamente em marketing, mas possui o quadro de vendedores atuando na prospecção constante para fidelizar clientes. Em paralelo, utiliza uma rede social para divulgar e manter um contato de relacionamento e mantem um site para formulário e pedidos eletrônicos.

Quanto à questão ambiental, o diretor relatou sua preocupação com o acúmulo de descarte de materiais. As atividades da Grampel precisam estar amparadas e geridas por lei ambiental. A Licença Ambiental de Operação - LAO autoriza o funcionamento de equipamentos de atividades e serviços e dá continuidade ao licenciamento efetuado. A LAO possui prazo de validade, pois é acompanhada por vistorias para verificar se a indústria atende às restrições e contribuições ambientais. Os resíduos da Grampel são recolhidos por empresas certificadas e a indústria vende a sucata mediante à emissão de nota fiscal da compradora, para comprovar o correto recolhimento dos resíduos. Esses apresentam formatos, peso e espessuras variadas, devido à prestação de serviços de acordo com a demanda. Os tipos de descarte não tem rotina de pedidos, mas recebe-se cerca de um pedido a cada trimestre, ou cerca de 40 peças.

Após a observação interna na Grampel, inicia-se a compilação dos pontos fortes e fracos detectados (figura 02). Os pontos fortes e fracos relacionados foram pautados com as visitas, observações e relatos coletados de acordo com os requisitos estabelecidos para análise interna. 


\begin{tabular}{|l|l|}
\hline PONTOS FORTES & PONTOS FRACOS \\
\hline $\begin{array}{l}\text { Apresenta Recursos Industriais e } \\
\text { Financeiros Adequados }\end{array}$ & $\begin{array}{l}\text { Inabilidades Técnicas de Produtos Fora do } \\
\text { Contexto Metal Mecânico }\end{array}$ \\
\hline Aspira Desenvolver e Investir em & Falta de Definições Estratégicas de \\
Nova Atuação Mercadológica & Design e Branding \\
\hline Considera Branding e Design & Baixo Investimento em Design e \\
como Fatores Importantes & Pesquisas de Mercado \\
\hdashline Conhecimento Amplo da & Falta de Designers para \\
Matéria Prima & Desenvolvimento de Produtos \\
\hline Possibilidade de Planejamento & Falta de Posicionamento de Mercado e \\
Sustentável pela Sucata e Residuos & Foco no Segmento de Produto \\
\hline Possibilidade na Competitividade de & Impossibilidade de Divulgação de \\
Produtos pelo Custo & Processos e Serviços em Profundidade \\
& para Terceiros (parcerias) \\
\hline
\end{tabular}

Figura 02 - Elaborado pelo autor com base na pesquisa realizada

Fonte: Elaborado pelos autores, com base na pesquisa realizada (2014)

Também verificaram-se as características dos resíduos gerados pela indústria (figura 03). Após análise dos retalhos, considera-se a pré-produção como melhor opção de intervenção. Para estipular as características quanto ao material e ao processo que poderá ser utilizado na nova atuação mercadológica, considera-se o fator do aproveitamento de retalhos da pré-produção dos pedidos recorrentes à indústria. Esse modo de aproveitamento evita o retalho, já que a indústrla inclui o projeto de novos produtos e/ou suas partes, na produção articulada com os pedidos, gerando uma competitividade mercadológica pelo melhor aproveitamento da chapa do alumínio. As peças de retalhos pós-produção são descartes do material provenientes de pedidos e que não pode integrar os espaços vagos para aproveitamento na linha de produção, por apresentar um custo elevado devido às dimensões reduzidas. Sendo assim, indica-se o aproveitamento melhor da chapa na própria linha de produção (préprodução). Mediante o exposto, as características do material e processos partem do princípio de estipular um direcionamento para esta pesquisa obter foco em determinado campo possível de inovação dentro da viabilidade da indústria.

Diante dessas verificações, constatou-se uma demanda significativa de pedidos com retalhos de descarte passíveis de intervenções. Após a possível criação de produtos e dentro das características e particularidades do material, salienta-se a possibilidade de o produto ser planejado no setor de engenharia de processos, considerando o aproveitamento da chapa e evitando o descarte final de retalho.

Tais características de materiais podem ser apresentadas e fomentar uma maneira de esclarecer a capacidade produtiva, possibilidades e limitações da Grampel para o novo mercado. Desse modo, as informações ordenadas das características podem fazer parte de um possível briefing para o designer de produtos que criará as novas peças. Com isso, tem-se a necessidade de iniciar a pesquisa referente ia análise externa e direcionar ainda mais o posicionamento e as possibilidades de atuação. 


\section{SÍNTESE DA ANÁLISE EXTERNA}

A análise externa, dentro da ferramenta SWOT é responsável por identificar ameaças e oportunidades impostas pelo cenário externo. Permite a organização de ideias a fim de poder tirar proveito de oportunidades apontadas ou precaver-se de possíveis ameaças. Diante das características levantadas na análise interna, considerou-se primordial que a análise externa contemplasse produtos com a mesma matéria prima, ou seja, o alumínio. Dentro deste contexto observaram-se as opções consideradas nos relatos do diretor, direcionando a análise pelo material com pequenas dimensões, processos utilizados de corte a laser, solda e dobra bem como a espessura definida, aspectos restritivos da Grampel.

O alumínio é um material reciclável, para fabricação de novas peças e produtos, ele passa por um processo de fundição para gerar o material em estado líquido. Após o estado líquido são realizados procedimentos que podem gerar produtos por meio de moldes ou em chapas para voltar a cadeia produtiva industrial. Por isso este material é considerado $100 \%$ reciclável. Entretanto a intenção de utilizar o alumínio no processo de produção da indústria, não contempla a fundição do material e sim o aproveitamento melhor da chapa dentro do próprio processo de corte. Todavia, após a criação e comercialização do produto, o mesmo ainda pode voltar a cadeia produtiva sendo descartado e voltando ao processo de reciclagem e fundição descritas.

Diante da intenção de contemplar os requisitos e restrições, tem-se na análise externa a compilação de alguns produtos dispostos no mercado com a utilização do material foco da pesquisa. Consideram-se ainda fatores como montagens e desmontagens de peças bem como a composição com outros materiais. Dessa forma podem-se oferecer maiores diferenciações de produtos atribuindo o material de base, o alumínio, em aproveitamento de chapas de retalhos. A possibilidade de aplicar outros materiais que a indústria não contempla em seus processos, possibilita uma maior diferenciação e criatividade, pois o designer terá menos restrições para criar. Para ilustrar alguns produtos no mercado apresenta-se na figura 13 um painel semântico com semelhanças de fabricação a partir das características restritivas da indústria e selecionados conforme definições do material.

O painel ilustrado na figura 04 foi elaborado com registros fotográficos da pesquisadora principal e com consultas em sites de busca de imagens como tendências, sendo selecionadas as que condizem com o material alumínio, cortes a laser e peças relativamente pequenas. Diante disso, visualizam-se possíveis atuações para o mercado de produtos em alumínio. Pode-se perceber alguns segmentos de atuação dentro do mercado decorativo como: decoração de parede, decoração com velas, decoração com letras, porta livros e decoração de bolos de casamentos.

Para possíveis atuações de mercado, atribuindo dados mercadológicos e definição de melhores estratégias no contexto econômico, estima-se o ramo de decoração como muito atrativo e com alto potencial de rentabilidade. Percebe-se ainda que o alumínio é bastante utilizado como material no segmento decorativo, já que possibilita o manejo diversificado, durabilidade, resistência e rigidez. Ainda nesse contexto, podem-se inserir segmentos mais objetivos, como coleções personalizadas, temáticas com datas festivas e outras opções de criação e desenvolvimento. 


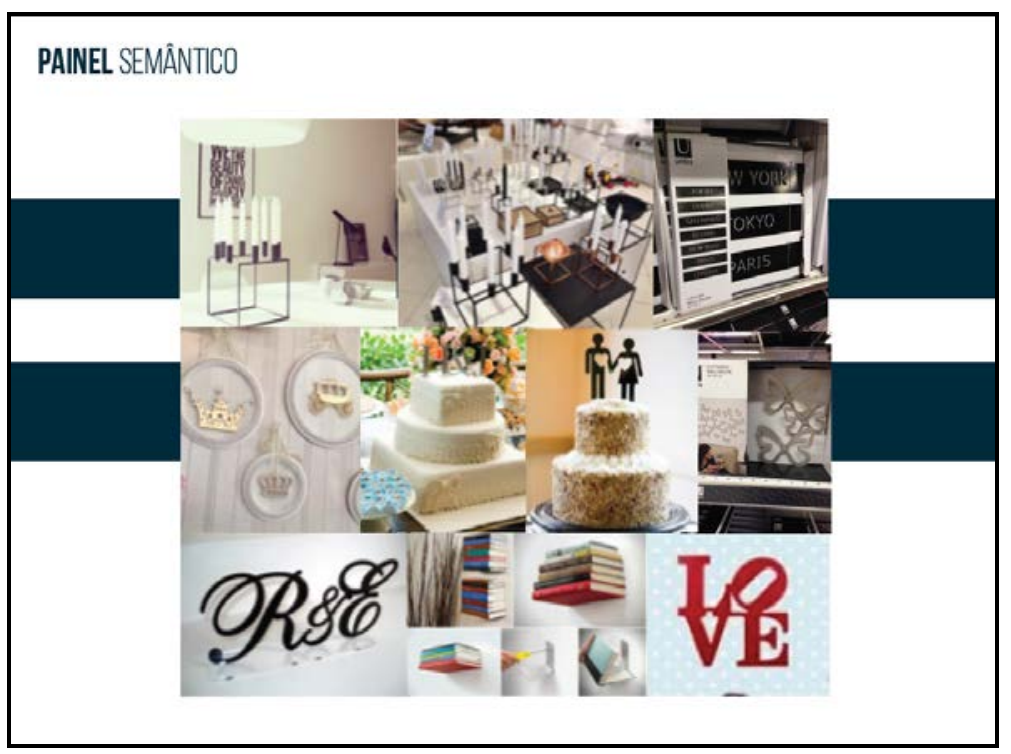

Figura 03 - Painel semântico de produtos em alumínio

Fonte: Elaborado pelos autores, com base na pesquisa realizada (2014)

Para análise externa visualizar possíveis concorrentes de atuação, foram selecionadas duas empresas para verificações de suas estratégias. As empresas foram selecionadas por comercializarem peças com os requisitos estabelecidos na pesquisa e produtos relacionados ao painel ilustrado na figura 04, sendo premissas: material alumínio, corte a laser e pequenas dimensões. Para denominar as empresas em questão, utiliza-se as letras $X$ e $Y$, evitando a divulgação sem a prévia autorização legal.

A empresa $X$ iniciou suas atividades na década de 1980. Cria, desenvolve e distribui objetos de decoração para todo Brasil em lojas multimarcas e franquias. São produtos em diversos materiais, além dos artefatos em alumínio, com madeiras, tecidos e plásticos. Salienta-se que as peças são criadas sugerindo experiências de consumo diferenciadas ao público, celebrando temáticas como família, amigos, lazer, bons momentos e satisfação. Em apenas quatro anos, a empresa já havia desenvolvido um sistema de franquias com quinze lojas. Atualmente, são 145 lojas exclusivas em todo Brasil, comercializando também em e-commerce, com outras marcas não próprias. A equipe tem 750 profissionais em escritórios de franquias, escritório de criação de produtos e centro de distribuição. O crescimento e consolidação da empresa $X$ são atribuídos ao fato de permanecerem com a premissa do design, sendo referência em inovação, design e diversão no desenvolvimento de produtos.

A empresa $Y$ assemelha-se à $X$ quanto à comercialização de produtos com materiais diversos. No segmento decorativo, a empresa $Y$ destaca peças wallart (arte de parede). Nessa atuação, desenvolve produtos em alumínio e cortes a laser para decoração de paredes. Outros utensílios diários e de cozinha também são encontrados em alumínio, mas possuem características que diferem das necessárias à indústria, pois são elaboradas com moldes e derretimento do alumínio, não sendo possível fabricá-las com recortes de chapa, solda e dobra. A empresa $Y$ iniciou suas atividades há trinta anos. Com exportação para o mundo todo, é referência em produtos com design criativo, possuindo uma equipe interna internacional de criação, pesquisando demandas que permitem avançar a gama de clientes e culturas. 
Conforme Aaker (2001), a análise externa compila elementos externos à organização, que são estratégicos e fomentam a verificação de oportunidades e ameaças em um comparativo para a organização. Desse modo, elaborou-se o quadro 01 compilando dados, estratégias e fatores chaves, verificou-se as duas concorrências apuradas, como também o mercado de atuação do segmento decorativo.

Dentre as estratégias da concorrência, evidenciou-se a preocupação com design no desenvolvimento e divulgação dos produtos. Ambas empresas possuem centros de criação nos quais a pesquisa e renovação constantes são premissas para a inovação e consolidação no mercado. As coleções sazonais também fazem parte da inovação constante na estratégia das empresas, desenvolvendo produtos temáticos para determinadas datas de comércio varejista. Outra característica recorrente é a comercialização em lojas físicas próprias e também online. Observa-se também que os produtos possuem apelo emocional e diferenciação com design agregado. Isso se dá pelo fato de serem projetados e criados com o planejamento devido, em centros de pesquisas de tendências e verificação constante do público alvo e clientes. Segundo o portal Varejista, em 2013, os brasileiros gastaram $8 \%$ a mais em artigos de decoração que no ano anterior. Avalia-se que a classe B é a que apresenta maior potencial de consumo, com cerca de R\$2,3 bilhões gastos em 2013.

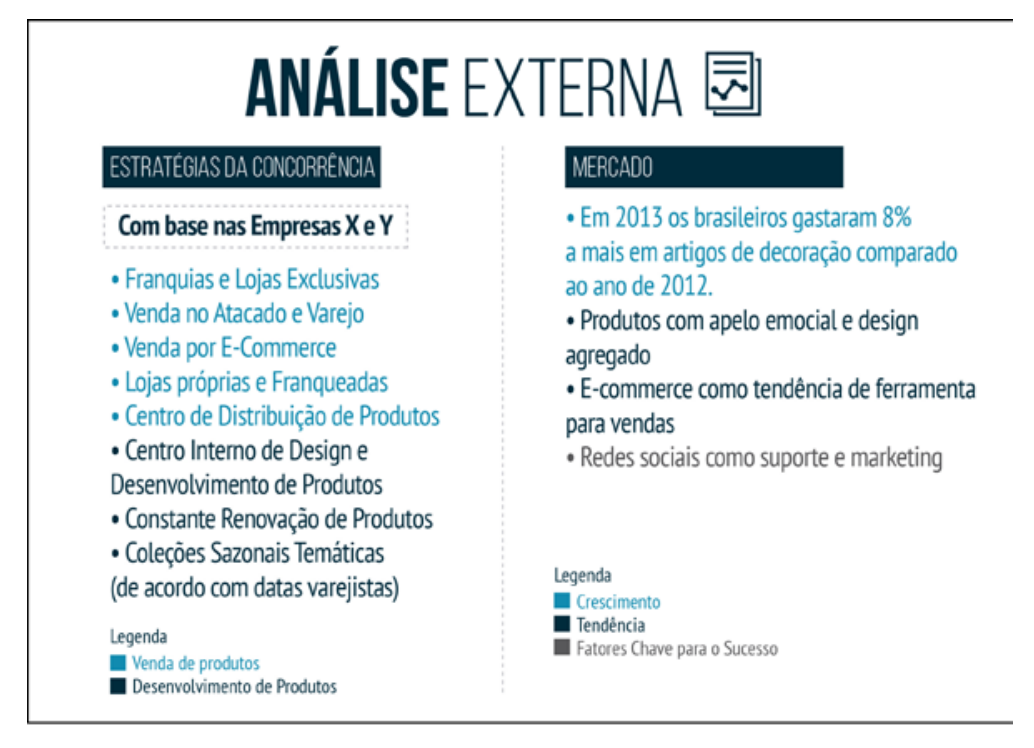

Quadro 01 - Análise externa

Fonte: Elaborado pelos autores, com base na pesquisa realizada (2014)

Para demonstrar o perfil de possíveis clientes nesse segmento, elaborou-se um mapeamento baseado em percepções obtidas nas análises dos concorrentes verificados, melhor ilustradas na figura 05.

Conforme Aaker (2001) aborda, alguns consumidores se preocupam em funções superiores e benefícios afetivos ao uso simples e comum de um produto. Tendo em vista esse perfil abranger homens e mulheres em uma faixa etária ampla, percebe-se que tendem a ser pessoas que lidam com tecnologias, pois consomem mais produtos pelo acesso de compras e vendas online. Também se verifica que as redes sociais estão presentes diariamente na vida das pessoas, as quais buscam socialização, compartilhamento, além de entretenimento e lazer no seu cotidiano, elegendo produtos que contemplem esse perfil. 


\section{PERFIL DE CLLENTES}

Mapeamento Baseado em Percepções e Possíveis Concorrentes

- Faixa Etária de 15 a 40 Anos

- Homens e Mulheres

- Classe Ae B

- Consumistas

- Procuram Novidades e Lançamentos diferenciados

- Procuram Envolvimento Afetivo e emocional em produtos

- Preocupam-se com Entretenimento e Lazer

- Lidam com Tecnologia

- Buscam Socialização, Compartilhamento e Inclusão

Figura 04 - Mapeamento de perfil de clientes

Fonte: Elaborado pelos autores, com base na pesquisa realizada (2014)

Contudo, a análise externa apresenta as oportunidades e ameaças verificadas no mercado externo (quadro 02). As oportunidades e ameaças embasaram-se na análise de duas possíveis empresas concorrentes. Diante disso, verificaram-se estratégias dessas empresas amparadas pelo composto de requisitos definidos, que forneceram suporte como foco de análise tanto externa como internamente. Devido ao funcionamento empresarial da Grampel seguir um sistema de prestação de serviços industriais, a indústria não possui um produto seriado, sendo essa a principal oportunidade de articulação. A ação da indístria se limita a projetos terceirizados e oriundos de empresas que fazem cotação em diversos outros concorrentes do segmento metalúrgico de corte a laser.

\begin{tabular}{|l|l|}
\hline OPORTUNIDADES & AMEAÇAS \\
$\begin{array}{l}\text { Possivel redução de } \\
\text { sucata }\end{array}$ & $\begin{array}{l}\text { Evolução de produtos importados da China } \\
\text { com valores reduzidos }\end{array}$ \\
\hline Sustentabilidade econômica & Cópias de produtos \\
\hline $\begin{array}{l}\text { Diversificação para nova área de } \\
\text { mercado promissora. }\end{array}$ & $\begin{array}{l}\text { Falta de conhecimento da concorrência e } \\
\text { mercado de atuação }\end{array}$ \\
\hline $\begin{array}{l}\text { Possibilidade de planejamento } \\
\text { sustentável pela sucata e residuos }\end{array}$ & $\begin{array}{l}\text { Falta de posicionamento de mercado e } \\
\text { foco no segmento de produto (novo entrante) }\end{array}$ \\
\hdashline $\begin{array}{l}\text { Possibilidade na competitividade de } \\
\text { produtos pelo custo }\end{array}$ & Concorrência estabelecida e posicionada \\
\hline Possiveis parcerias e contratações & Lojas fisicas estabelecidas além de virtuais \\
\hline
\end{tabular}

Quadro 02 - Oportunidade e ameaças

Fonte: Elaborado pelos autores, com base na pesquisa realizada (2014) 


\section{INFOGRÁFICO}

Para ilustrar a gestão do design na Grampel elaborou-se um infográfico para visualização das estratégias sugeridas. O infográfico elaborado teve a preocupação de amparar as diretrizes hierarquicamente e de forma explicativa. Considerando o diagnóstico realizado durante a etapa de imersão e todos os dados coletados, foi possível realizar na fase de ideação as definições estratégicas necessárias para a indústria criar uma nova atuação mercadológica. Neste sentido, apresenta-se o infográfico desenhado com as sugestões indicadas e relatadas no estudo.

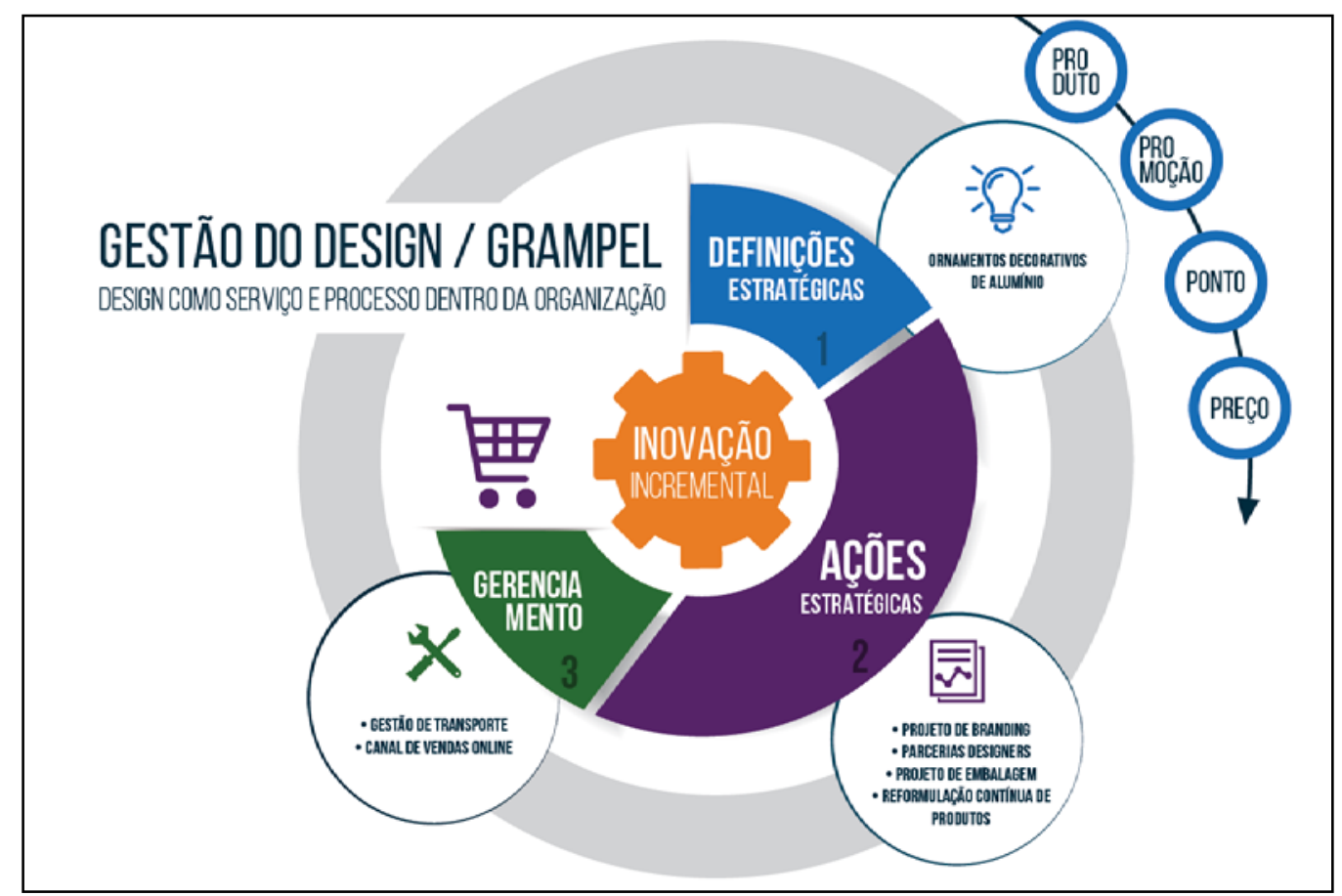

Figura 05 - Infográfico

Fonte: Elaborado pelos autores, com base na pesquisa realizada (2014)

\section{CONSIDERAÇÕES FINAIS}

Para realizar possíveis intervenções do design na indústria Grampel, foi necessário um extenso processo de estudo e análises para realização e desenvolvimento de um diagnóstico. Dessa maneira, esta pesquisa utilizou o aporte teórico da gestão, do marketing e do design como uma oportunidade atrativa para viabilizar a nova atuação de mercado pretendida. As principais conclusões do diagnóstico estratégico foram apresentadas por meio da ferramenta SWOT, possibilitando aos gestores e colaboradores da indústria uma maneira fluída e com bom senso cognitivo para leitura e compreensão dos resultados obtidos.

Dentro do contexto da indústria, elimina-se a ideia de o desenvolvimento de produtos ser necessariamente o fator primordial para o êxito e a inovação de uma organização. Buscou-se, por meio da pesquisa, evidenciar a relevância da compreensão do processo e do design atuando em serviços, para guiar a inovação no desenvolvimento de novos produtos e mercados. Pelo recente surgimento e discussão da real atuação acerca do design em áreas administrativas, é recorrente a dificuldade de integração e entendimento dos designers com os profissionais gestores já atuantes na organização. Visto que a gestão do design visa organizar e coordenar atividades criativas da organização e com ferramentas desprendidas da concepção tradicional 
administrativa. Percebeu-se que com a visão interdisciplinar dessa atuação e buscando ferramentas propícias, pode-se agregar maiores possibilidades de atuação dos profissionais junto às indústrias, gerando resultados mais inovadores.

Nesse sentido, esta pesquisa contribuiu no desenvolvimento da ciência e da prática, no que diz respeito às áreas de design, gestão, inovação e marketing na indústria. Também sugere-se aprofundar algumas abordagens teóricas, visto que a pesquisa se limitou ao diagnóstico estratégico, podendo enriquecer em desdobramentos futuros com os pilares da sustentabilidade, desenvolvimento de produtos e outro campos de conhecimento que o designer pode contribuir junto da indústria, propondo soluções tangíveis e aplicáveis.

Repensar os processos e diagnosticá-los por meio do design representa possíveis melhorias e inovações em uma organização, desse modo, pode-se garantir maior competitividade mercadológica e contribuir de maneira acadêmica para possíveis novos desdobramentos de estudo.

\section{REFERÊNCIAS}

AAKER, David A. Administração Estratégica de Mercado. 5. ed. Porto Alegre: Bookman, 2001.

BROWN, Tim. Design Thinking: uma metodologia poderosa para decretar o fim das velhas ideias. Rio de Janeiro: Elsevier, 2010.

KOTLER, Philip. Marketing de A a Z. São Paulo: Editora Campus/Elsevier, 2003.

MARTINS, Rosane Fonseca de Freitas; MERINO, Eugenio Andrés Díaz. Gestão de Design como Estratégia Organizacional. 2.ed. Londrina: EDUEL, 2011.

MOZOTA, Brigitte Borja de. Gestão do Design: Usando o design para construir valor de marca e inovação corporativa. Porto Alegre: Bookman, 2011.

OLIVEIRA, Djalma de Pinho Rebouças de. Planejamento Estratégico. Conceitos, metodologia e prática. Edição 28. São Paulo: Atlas, 2010.

VIANNA, Mauricio et al. Design thinking: inovação em negócios. Rio de Janeiro: MJV Press, 2012. 